\title{
Finite element analysis of retaining wall for high slope
}

\author{
Yingzhou Yan ${ }^{1, \text { a }}$, Yiqing Liu $^{1}$, Xiaochun Zhang ${ }^{1}$ and Daofang Wang ${ }^{2}$ \\ ${ }^{1}$ School of transportation, Southeast University, Nanjing, 210000, China \\ ${ }^{2}$ Taizhou city traffic investigation and design institute,Taizhou,318000, China, E-mail: TZWDF7022@163.com
}

\begin{abstract}
To analyze and summarize the actual characteristics of retaining wall under different circumstances, which include nature soil, soil in different degree of compaction and soil with anchors, a finite element model is established according to an expressway widening project, which includes a gravity retaining wall up to $18 \mathrm{~m}$. Results show that displacement to the outside of retaining wall happens with tensile stress generates in the inner side, which is positively correlated to the degree of compaction of the soil behind the retaining wall. In addition, it turns out to be the case that adding anchor rods can be effective in ensuring the stability of retaining wall for high slope.
\end{abstract}

Keywords: high slope, retaining wall, finite element.

\section{Introduction}

In recent years, large number of highway constructions in mountain areas lead to many failure accidents in high slopes. Such as a retaining wall in Linan, southern Hunan, turned to crack after continuous heavy rainfall[1], which has brought great influences on the safety of slope and highway engineering. Many researchers have carried out numerical simulation on the stability of different types of retaining walls. Luan Mao-tian et al.[2] made discussion on the performance of geotechnical grid retaining walls by using finite element method. The relationship between design and performance of retaining walls were studied by Clough (1972)[3], Shaarawi (1980)[4].

To analyze and summarize the actual characteristics of retaining wall under different circumstances, a finite element model is established according to an expressway widening project, which includes a retaining wall up to $18 \mathrm{~m}$. In addition, the layout scheme of anchor rods is optimized in this paper, which may provide reference for the construction and design of retaining wall in high slope.

\section{Engineering situation}

A highway project took advantage of existing subgrade in order to widening the foundation to $23 \mathrm{~m}$, which located on the slope outside the old embankment. Simple retaining walls were placed there, plane position and actual terrain of the slope is shown in Fig. 1 and Fig. 2.

${ }^{\mathrm{a} C}$ Corresponding author : luckerant@163.com 


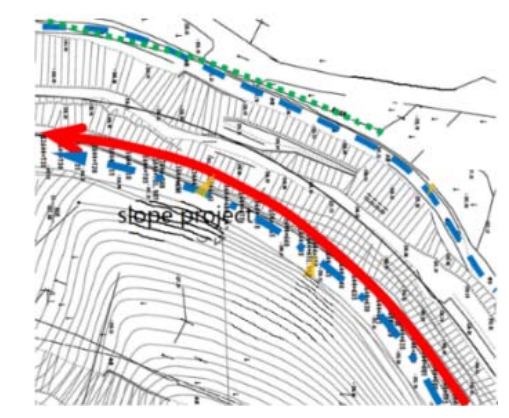

Figure 1. Plane sketch of slope.

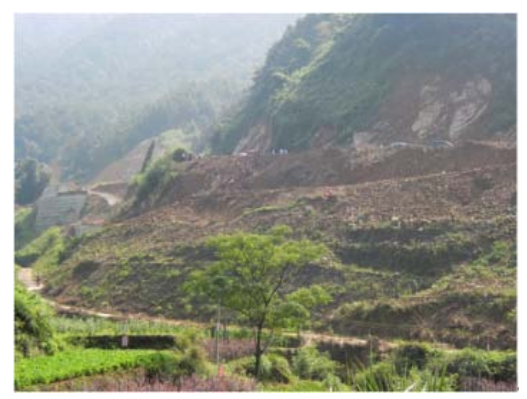

Figure 2. Actual terrain of slope.

\section{Finite element model}

\subsection{Calculation parameters}

As main supporting structure, the lower retaining wall has reached $18.02 \mathrm{~m}$. Anchors used in reinforcement were $436 \mathrm{HRB} 335$, with length of $20 \mathrm{~m}$, distance of $2.5 \mathrm{~m}$, and dip 90 degrees in default. Backfill soil was simplified as elastic plastic, while the other materials were considerd continuous, perfectly elastic, homogeneous and isotropic. Main material parameters used in the model are shown in Table 1.

Table 1. Main material parameters.

\begin{tabular}{|c|c|c|c|c|c|}
\hline & $\begin{array}{c}\text { Elastic } \\
\text { modulus(Gpa) }\end{array}$ & $\begin{array}{c}\text { Poisson } \\
\text { ratio }\end{array}$ & $\begin{array}{c}\text { Density( } \\
\left.\mathrm{KN} / \mathrm{m}^{3}\right)\end{array}$ & $\begin{array}{c}\text { Friction } \\
\text { angle } \\
\left(\sum\right)\end{array}$ & $\begin{array}{c}\text { Cohesion } \\
\left(\mathrm{kN} / \mathrm{m}^{2}\right)\end{array}$ \\
\hline Concrete & 25.5 & 0.16 & 23 & & \\
\hline Backfill & 0.15 & 0.35 & 21 & 24 & 30 \\
\hline $\begin{array}{c}\text { Original } \\
\text { slope }\end{array}$ & 5.5 & 0.30 & 32 & & \\
\hline Anchor & 200 & 0.20 & 78 & & \\
\hline
\end{tabular}

\subsection{Selection and types of cells}

A total of 23172 elements, including 22925 C3D8R solid elements (retaining wall and soil) and 247 T3D2 bar elements (anchors) were generated in this paper.

\subsection{Constraint and loading condition}


The bottom of the foundation was fixed. Horizontal direction of the front and rear sides was set and the displacement of the vertical direction was allowed. Both sides of the soil and retaining wall of Y direction were restricted while displacement in the vertical direction was allowed. In addition, top surfaces of slope and retaining walls were free.

Binding constraints were adopted between original slope and artificial fillings, while frictional constraints were placed between the inner surface of retaining walls and artificial fillings. The friction coefficient was set 0.3 .

\subsection{Calculation conditions}

(1) Artificial fillings in different compaction degree;

(2) Optimal arrangement scheme of anchors.

\section{Result analysis}

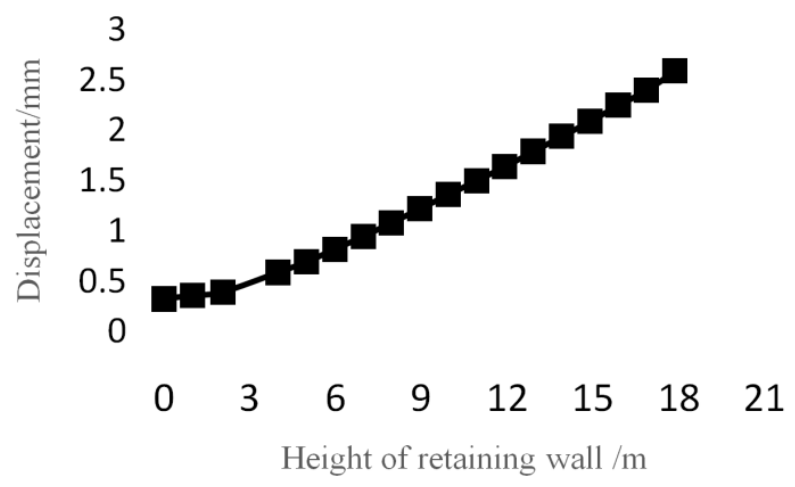

Figure 3. Distribution of displacement.

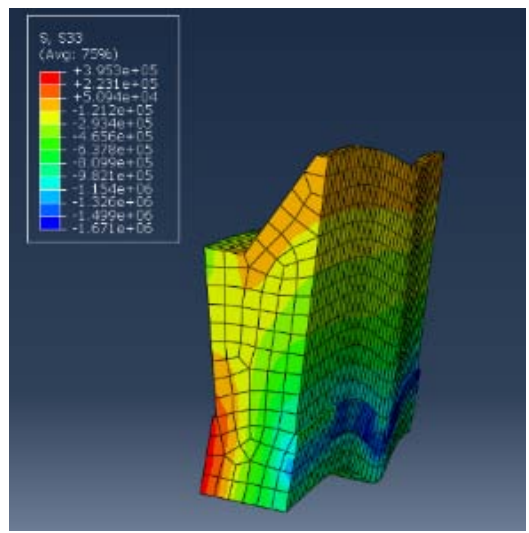

Figure 4. Vertical stress distribution of retaining wall.

\subsection{Displacement and stress distribution of retaining wall}

Displacement results in Fig. 3 has indicated that displacement orienting to the airport was produced under self-weight and lateral pressure. Maximum displacement, $2.771 \mathrm{~mm}$, took place in the top of the retaining wall and kept decreasing along the vertical direction.

It can be seen from the results in Fig. 4 that the maximum compressive stress of retaining wall appeared near the airport side edge, which up to 1.73MP, while the maximum tensile stress appeared 
near the inner side of retaining wall, which up to $0.49 \mathrm{MPa}$, which is consistent with the result of displacement results.

Table 2. Strength index of subgrade-soil with different compaction degree[5].

\begin{tabular}{|c|c|c|c|}
\hline $\begin{array}{c}\text { Compaction } \\
\text { degrees (\%) }\end{array}$ & $\begin{array}{c}\text { Density } \\
\left(\mathrm{kg} / \mathrm{m}^{3}\right)\end{array}$ & $\begin{array}{c}\text { Cohesio } \\
\mathrm{n} \\
\left(\mathrm{kN} / \mathrm{m}^{\wedge}\right. \\
2)\end{array}$ & $\begin{array}{c}\text { Friction } \\
\text { angle } \\
\left(\sum\right)\end{array}$ \\
\hline 90 & 2100 & 30 & 24 \\
\hline 93 & 2270 & 52 & 26 \\
\hline 96 & 2350 & 65 & 27 \\
\hline 99 & 2370 & 70 & 29 \\
\hline
\end{tabular}

In fact, the compaction situation of backfill soil is complex and difficult to be determined. Backfillsoil of four different compaction degree $(90 \%, 93 \%, 96 \%, 99 \%)$ were considered in this paper. Specific parameters were shown in Table 2.

Results in Fig. 5 shows that with the compaction degree varies from $90 \%$ to $99 \%$, the maximum displacement of retaining wall toward airport increased by $10.7 \%$, which shows that the increase of compaction degree of backfill soil behind retaining wall is disadvantageous to the stability of retaining wall.

It can be seen from the stress calculation results in Fig. 6 that, with the degree of compaction varies from $90 \%$ to $99 \%$, the maximum compressive stress on the outside of retaining wall increased by $7.9 \%$, the maximum tensile stress increased by $17.7 \%$. The improvement of compaction degree of backfill soil is unfavorable to the stability of retaining wall.

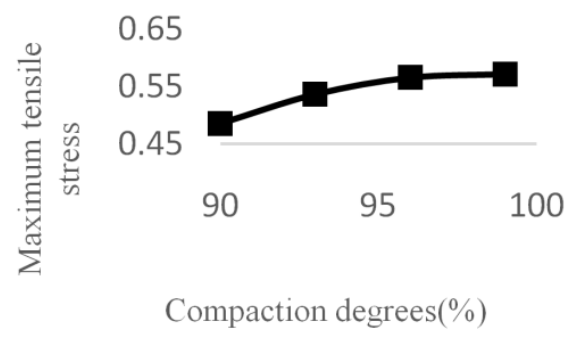

Figure 5. Displacement in different compaction degree.

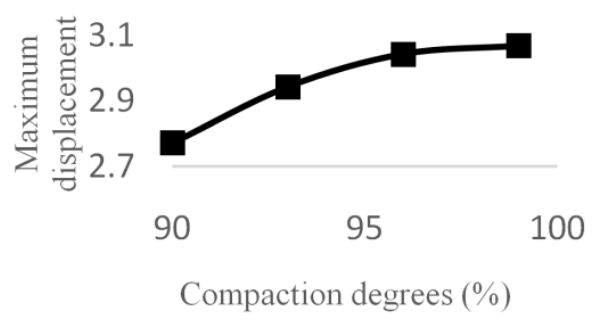

Figure 6. Stress distribution of retaining wall.

\subsection{Optimal layout scheme of anchors}

Anchors were arranged in spacing of $2.5 \mathrm{~m}$, as a total of 19 anchors along the subgrade. Default anchor angle is horizontal and default anchoring position is on the edge of tensile stress distribution area of the retaining wall (about $7.8 \mathrm{~m}$ from the bottom according to the calculation). 


\subsubsection{Optimal anchoring angle}
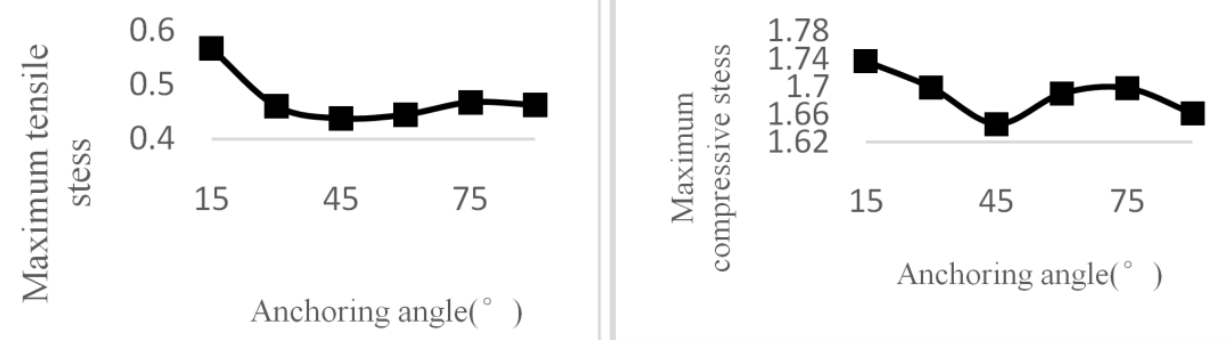

$15 \quad 45 \quad 75$

Anchoring angle $\left({ }^{\circ}\right)$

Figure 7. Relationship between stress and anchoring angle.

Calculation results in Fig. 7 shows that, maximum tensile stress and compressive stress are significantly reduced after adding anchors, which means that adding anchors is conducive to the stability of the retaining wall. What's more, reinforcement is most effective when anchoring angle is about 45 degrees.

\subsubsection{Optimal anchoring position}

Maintain the anchoring angle of $45^{\circ}$ and change the anchor position from $5.8 \mathrm{~m} \sim 10.8 \mathrm{~m}$ ( distance from the bottom of retaining wall).
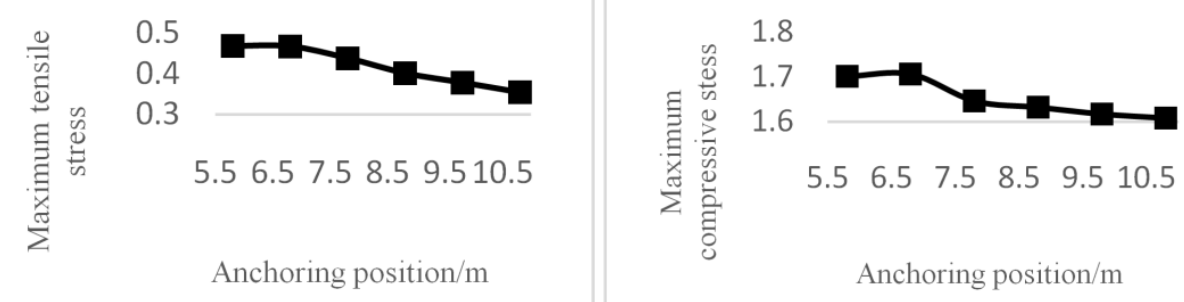

Figure 8. Relationship between stress and anchoring position.

From the results in Fig. 8, we can see that with the increase of anchoring position, maximum tensile stress, maximum compressive stress were gradually reduced, which means reinforcement effect and anchoring position is positively related.

Basing on all above calculation, we can conclude that when the anchor angle is 45 degrees and anchoring position is as higher as posible, the reinforcement effect is the best. Therefore, we determined the optimal anchorage scheme: anchoring angle 45 degrees, anchor position is $10.8 \mathrm{~m}$ from the bottom of the retaining wall.

After adopting the optimal anchoring scheme, the varieties of maximum displacement toward airport and stress distribution are shown in Fig. 9.

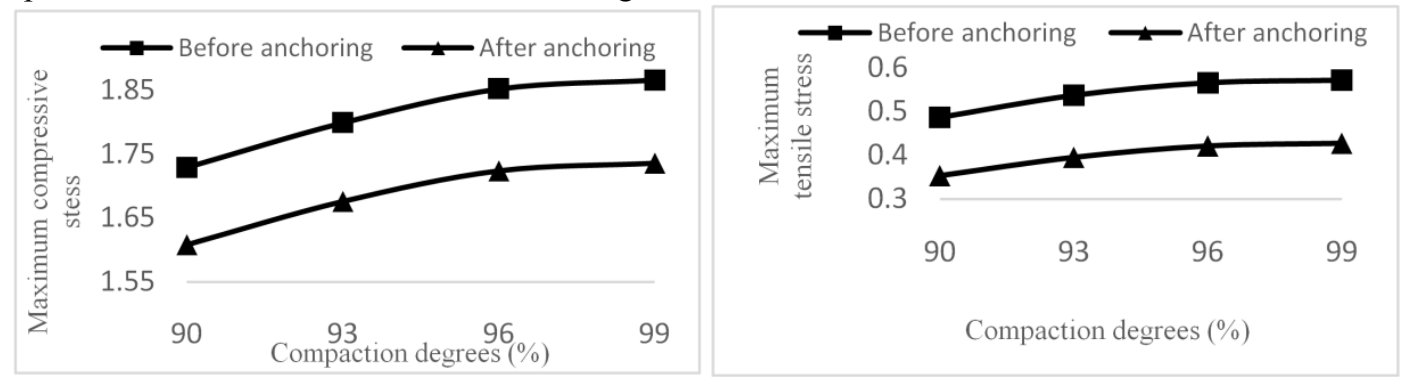

Figure 9. Variation of stress of retaining wall after anchoring. 
It can be seen from the contrast that maximum tensile stress has reduced by $27.16 \%$, while maximum compression stress has reduced by $7.00 \%$, which means that the stability of retaining wall is significantly enhanced after anchorage.

\section{Conclusions}

Following conclusions could be obtained basing on calculation results;

(1) Displacement of retaining wall orienting to the airport has taken place under self-weight and lateral pressure in high slope. Maximum displacement took place in the top of retaining wall and kept decreasing along vertical direction. In addition, tensile stress and displacement towards airport have increased with the growing of compaction degree of backfill soil behind retaining wall.

(2) Adding anchors can effectively reduce the displacement of retaining wall towards airport and tensile stress in inner side of retaining wall, which means promising results in enhancement of retaining wall in high slope. We can conclude that, basing on above calculation, when anchor angle is 45 degrees and anchoring position is as higher as posible, the reinforcement effect is optimal.

\section{References}

1. Qi-xingWU, Guan-fengTIAN,Yong-zhou CHEN. Analysis and lessons from a gravity retaining wall accident[J]. Subgrade Engineering,2003,02:36-37.(In Chinese)

2. Mao-tianLUAN,Jing-feng LI, Cheng-zhiXIAO, QingYANG, Jian-junFei. Nonlinear finite element analysis of working performance of reinforced retaining[J].Chinese journal of rock mechanics and engineering,2005,14:2428-2433.(In Chinese)

3. Clough,G.W. and Tusi,y. Performance of tie-back wall in clay. Proceeding, American society of civil engineers[J]. vol100, No.Gt12,1974,1259-1273.

4. Shaarawi,E.E. Some aspects of the numerical modeling of earth retaining structures[D]. University of Bristol,1980.

5. Jun-pingYUAN, JunZHAN, Shen-chaoCHEN,Kang-bo LI. Effect of moisture content and compaction degree on mechanical properties of subgrade soil[J]. Journal of Water Resources and Architectural Engineering,2013,02:98.(In Chinese) 